\title{
Claude Burgelin, Les Mal Nommés: Duras, Leiris, Calet, Bove, Perec, Gary et quelques autres
}

\section{Elena Quaglia}

\section{(2) OpenEdition}

1 Journals

\section{Édition électronique}

URL : http://journals.openedition.org/studifrancesi/1627

DOI : 10.4000/studifrancesi. 1627

ISSN : 2421-5856

Éditeur

Rosenberg \& Sellier

\section{Édition imprimée}

Date de publication : 1 novembre 2014

Pagination : 637

ISSN : 0039-2944

\section{Référence électronique}

Elena Quaglia, «Claude Burgelin, Les Mal Nommés: Duras, Leiris, Calet, Bove, Perec, Gary et quelques autres ", Studi Francesi [En ligne], 174 (LVIII | III) | 2014, mis en ligne le 01 novembre 2014, consulté le 18 septembre 2020. URL : http://journals.openedition.org/studifrancesi/1627 ; DOI : https://doi.org/ 10.4000/studifrancesi. 1627

Ce document a été généré automatiquement le 18 septembre 2020.

\section{(c) 9 (i) $\Theta$}

Studi Francesi è distribuita con Licenza Creative Commons Attribuzione - Non commerciale - Non opere derivate 4.0 Internazionale. 


\title{
Claude Burgelin, Les Mal Nommés: Duras, Leiris, Calet, Bove, Perec, Gary et quelques autres
}

\author{
Elena Quaglia
}

\section{RÉFÉRENCE}

Claude BuRgelin, Les Mal Nommés: Duras, Leiris, Calet, Bove, Perec, Gary et quelques autres, Paris, Seuil, 2012 («La Librairie du XXI ${ }^{\mathrm{e}}$ siècle»), pp. 368.

1 Claude Burgelin livre dans cette étude une analyse du rapport souvent complexe que certains auteurs entretiennent avec leur nom propre. Le nom propre devient une clé de lecture de l'œuvre littéraire, une porte d'accès à l'univers de plusieurs romanciers du $\mathrm{xx}^{\mathrm{e}}$ siècle. L'approche choisie par Burgelin est d'autant plus significative dans le cas des écritures du “Je", où l'on assiste à l'émergence de plusieurs problématiques identitaires.

Dans son introduction, le critique s'engage dans une réflexion sur les différents enjeux liés au nom propre, et, en particulier, sur ses enjeux littéraires. Il insiste sur la dimension paradoxale du nom propre, qui recouvre en même temps les concepts de fixité et de changement, d'identité et de différence, de mémoire et de détachement, de sacralité et de banalité.

3 L'analyse littéraire s'attache surtout aux auteurs qui ont eu le sentiment d'être mal nommés et qui, de ce fait, ont eu souvent recours à des pseudonymes: l'invention d'un nouveau nom devient ainsi «le premier acte d'une création de soi-même comme auteur» (p. 22). Ce changement de nom se relie à des problématiques de l'ordre du biographique, du psychanalytique et surtout de la filiation: Burgelin souligne la centralité du rapport au père en ce qui concerne le malaise ressenti par certains auteurs envers leur patronyme. 
4 On voit donc défiler au cours du livre des auteurs tels que Marguerite Duras (Donnadieu de son vrai nom), Michel Leiris, Henri Calet, qui était né Raymond Barthelmess, Emmanuel Bove (Bobovnikoff), Georges Perec et Roman Kacew, mieux connu comme Romain Gary ou encore comme Émile Ajar: dans le nom de tous ces écrivains et dans les problèmes qu'il leur pose se cache l'un des principaux mobiles de leur création littéraire. Dans chaque chapitre Burgelin essaie de retracer, dans les troubles identitaires liés à l'enfance et au rapport avec les parents, l'une des racines des différentes œuvres qu'il analyse.

5 Dans sa conclusion le critique avoue avoir adapté sa démarche à chaque écrivain, en soulignant la singularité de chaque parcours et en laissant ainsi la voie ouverte à de nouvelles études critiques sur d'autres auteurs. Il est conscient du risque de se rapprocher de si près de problématiques individuelles, mais il revendique cet angle de lecture pour des textes qui «s'écrivent à partir de questionnements existentiels [...] issus de mémoires mises à mal, de paysages intérieurs brouillés» (p. 337).

6 L'inquiétude par rapport au nom propre se fait, dans ces écritures, objet de déformation et point de départ d'un nouveau rapport à la langue, un rapport créatif qui s'engage dans un questionnement identitaire inépuisable. Le nom des personnages est aussi souvent porteur de significations cachées, qui suggèrent l'incertitude définitoire du nom et minent sa fixité présumée. Le nom cesse d'être un marqueur de filiation et d'identité, il devient instable à l'image de l'écriture qui se déploie dans beaucoup d'œuvres $\mathrm{du} \mathrm{xx}^{\mathrm{e}}$ siècle, travaillées dans leur fond et dans leur forme par l'incertitude, l'errance et la quête. 